\title{
Animal Barrier Facility
}

National Cancer Institute

\section{Source}

National Cancer Institute. Animal Barrier Facility. NCI Thesaurus. Code C16024.

A shared facility which maintains a breeding stock of animals in a disease-free state. 